\title{
The effect of electric shock upon a nonlocomotor measure of exploration*
}

\author{
B. GILLEN $\dagger$ \\ Old Dominion University, Norfolk, Va. 23508
}

This experiment was conducted to investigate the effects of different levels of shock (control, $100 \mathrm{~V}$, or $200 \mathrm{~V})$ upon exploration. To avoid the possible pitfalls of previous research, nonlocomotor measures were used: the frequency of response and the total time spent viewing a novel stimulus. The results indicate an inverted U-shaped function between level of shock and the frequency of exploratory responses, with the $100-\mathrm{V}$ level generating high rates and control $\mathrm{V}$ and $200 \mathrm{~V}$ producing low rates. When the total time spent in viewing is considered, an inverse relationship is evident. As the shock level increases, the time in exploration decreases.

The effects of fear or anxiety upon exploratory behavior are unclear. The majority of research supports the contention that exploration is inversely related to the level of fear (Aitken \& Sheldon, 1970; Baron, 1963, 1964; Haywood \& Wachs, 1967; Montgomery, 1955; Montgomery \& Monkman, 1955; Mikulka, Kendall, Constantine, \& Porterfield, 1972). Though in a minority, there are a few studies which indicate that fear can also elicit approach behavior (Lester, 1968; Halliday, 1966).

In all of the studies noted, exploratory behavior or curiosity has been defined in terms of some measure of locomotor activity. It is possible that such a measure may be open to a number of interpretations. A high degree of locomotor activity may represent true exploration or escape behavior. A low amount of such activity may indicate a lack of exploration, a "freezing" response, or a high degree of exploration in a restricted area. Thus, even though significantly high or low amounts of locomotion are exhibited after the introduction of fear-producing stimuli, a clear-cut interpretation of the results may not be possible.

In the present experiment, a measure of exploration was used which was not dependent upon locomotor activity. Sales (1968) has designed an apparatus to study the effects of stimulus complexity upon the number and duration of exploratory responses. This apparatus is a two-compartment box; from one side the $\mathrm{S}$ can poke his head through a hole in the wall to view checkerboard patterns of various complexity in the second compartment. Sales found that inspection time per

*Special gratitude is expressed to Joseph Sever, Linda Porterfield, and Paula Rapisardi for their assistance in the construction of the apparatus and handling of the Ss used in this study. A grant from the National Science Foundation, No. GY-8437, provided partial support for this research. Peter J. Mikula sponsors this paper and takes complete editorial responsibility.

PPresent address: Department of Psychology, Miami University, Oxford, Ohio 45056. approach generated an inverted-U pattern as a function of stimulus complexity. This measure, then, yields a better index of exploration or curiosity than a simple locomotor measure.

\section{METHOD}

Subjects

The Ss were 30 naive hooded male rats from the Charles River Laboratory. All Ss were 100-120 days old and had been handled extensively prior to testing. During the course of the experiment, the animals were maintained on ad lib food and water.

\section{Apparatus}

The exploratory box was designed to be identical to that used by Sales (1968). The stimulus card that was used was made up of a 25 black and white checkerboard pattern. This pattern was chosen because it had elicited relatively high response rates in Sales's (1968) study.

The shock apparatus measured $12 \times 12 \times 7$ in. The floor consisted of grids $1 / 16$ in. in diam and spaced $1 / 4$ in. apart. The electric shocks were produced by a matched-impedance shock source $(150-\mathrm{k}$ ohms), set at 100 or $200 \mathrm{~V}$ and applied to the grids through a Lafayette Instrument Company Model A620 shock scrambler. The walls of the shock apparatus were bright aluminum, which contrasted with the flat-black color of the exploratory apparatus.

\section{Procedure}

The Ss were assigned randomly to one of three groups $(N=10)$ : the control group $(C)$, which received no shocks; the first experimental group (E100), which received a 100-V shock for $30 \mathrm{sec}$; or the second experimental group (E200), which received a $200-\mathrm{V}$ shock for $30 \mathrm{sec}$. Each $\mathrm{S}$ was taken from his home cage, handled for several minutes, and then placed in the shock apparatus where the correct level of shock was administered. The $\mathrm{S}$ was then removed from the shock apparatus and immediately placed in the exploratory situation for $8 \mathrm{~min}$. Two measures of exploration were noted for each S: the total time the $S$ had his head in the observation hole and the number of times each $S$ projected his head through the hole. The Ss were run at random times during the night and day, and no $S$ was used more than once in order to avoid any contamination due to previous experience.

\section{RESULTS}

A one-way analysis of variance was used for each of the two dependent variables. Scheffé tests were then conducted to compare differences in means where appropriate. The groups were significantly different in the amount of time spent exploring the stimulus card $(F=5.36, d f=2 / 27, p<.05)$. The mean total times for the C, E100, and E200 groups were 12.45, 10.12, and $7.24 \mathrm{sec}$, respectively. The total time spent in exploration by $\mathrm{C}$ corresponds almost exactly to the time obtained by Sales (1968). Scheffé comparisons revealed that the C and E100 groups were not different from each other, but both spent more time exploring the stimulus than the E200 group $(p<.01$ and $p<.05$, respectively). 
Analysis of the frequency of viewing found that the groups were significantly different $(F=16.78, \mathrm{df}=2 / 27$, $\mathrm{p}<.01)$. The mean frequency of viewing was 22.50 , 27.80 , and 10.60 for the C, E100, and E200 groups, respectively. Scheffe tests indicated that the E100 and E200 groups and the $\mathrm{C}$ and E200 groups were significantly different at the .01 level, and the $\mathrm{C}$ and E100 groups were different at the .05 level.

\section{DISCUSSION}

The results of this experiment show that increasing arousal level affects visual exploration. However, the arousal levels differentially affected the two dependent variables. Total observation time was found to be an inverse function of arousal level. This is consistent with the findings of other studies using locomotion as an index of exploration (Aitken \& Sheldon, 1970; Baron, 1963, 1964; Haywood \& Wachs, 1967; Montgomery, 1955; Montgomery \& Monkman, 1955; Mikulka et al, 1972).

If only the performance of the E200 Ss is considered, over both dependent variables these Ss are consistently less active and exploratory than the control Ss. Such a finding contradicts the Fowler-Jones theory (Fowler, 1965, 1967; Jones, 1961; Jones, Wilkinson, \& Braden, 1961), which holds that all sources of drive (including those relevant to shock) should have general energizing effects.

In contrast, the frequency of head poking was an inverted U-shaped function of shock level. This effect is primarily due to the increased response rate of the E100 Ss. This finding is consistent with Lester's (1968) theory, which emphasizes the point that low levels of aroused fear may lead to approach behavior, while higher levels of aroused fear may lead to avoidance behavior.

It is difficult to resolve the discrepancy in these two behavioral indices. One possibility is that the frequency of nose poking is a measure of activity level (i.e., escape behavior), while viewing time is a measure of exploration. It might be expected that activity (i.e., escape behavior) would increase with shock to a point, after which increased shock levels would elicit freezing behaviors. However, exploration (viewing time) is a decreasing function of the fear level, with the Ss evidencing shock-elicited escape or freezing behaviors.

\section{REFERENCES}

Aitken, P. P., \& Sheldon, M. H. Electric shock and rats' preference for the familiar arm of a maze. British Journal of Psychology, 1970, 61, 95-97.

Baron, A. Differential effects of fear on activity in novel and familiar environments. Psychological Report, 1963, 13, 251-257.

Baron, A. Suppression of exploratory behavior by aversive stimulation. Journal of Comparative \& Physiological Psychology, 1964, 57, 299-301.

Fowler, H. Curiosity and exploratory behavior. New York: Macmillan, 1965.

Fowler, H. Satiation and curiosity: Constructs for a drive and incentive motivational theory of exploration. In $\mathrm{K}$. W. Spence and J. T. Spence (Eds.), The psychology of learning and motivation. Vol. 1. New York: Academic Press, 1967.

Halliday, M. S. Exploration and fear in the rat. Symposium of the Zoological Society of London, 1966, 18, 46-59.

Haywood, H. C., \& Wachs, T. D. Effects of arousing stimulation upon novelty preference in rats. British Journal of Psychology, 1967, 58, 77-84.

Jones, A. Supplementary report: Information deprivation and irrelevant drive as determiners of an instrumental response. Journal of Experimental Psychology, 1961, 62, 310-311.

Jones, A., Wilkinson, H. J., \& Braden, I. Information deprivation as a motivational variable. Journal of Experimental Psychology, 1961, 62, 126-137.

Lester, D. The effect of fear and anxiety on exploration and curiosity: Toward a theory. Journal of General Psychology, 1968, 79, 105-120.

Mikulka, P., Kendall, P., Constantine, J., \& Porterfield, L. The effects of Pavlovian CS+ and CS- on open-field behavior. Psychonomic Science, 1972, 27, 308-310.

Montgomery, K. C. The relation between fear induced by nove stimulation and exploratory behavior. Journal of Comparative \& Physiological Psychology, 1955, 48, 254-260.

Montgomery, K. C., \& Monkman, J. A. Relation between fear and exploratory behavior. Journal of Comparative \& Physiological Psychology, 1955, 48, 132-136.

Sales, S. M. Stimulus complexity as a determinant of approach behavior and inspection time in hooded rats. Canadian Journal of Psychology, 1968, 22, 11-17.

(Received for publication November 15, 1972.) 